\title{
Rinosinüzit Komplikasyonu: İnatçı Subperiosteal Apse
}

\author{
Rhinosinusitis Complication: Persistent Subperiosteal Abscess
}

\section{İsa ÖZBAY ${ }^{1}$, Cüneyt KUCUR ${ }^{1}$, Onur ERDOĞAN ${ }^{1}$, Fatih OĞHAN ${ }^{1}$ Mehmet TETIKOĞLU ${ }^{2}$, Hacı Murat SAĞDIK ${ }^{2}$}

1. Dumlupınar Üniversitesi Tıp Fakültesi, Kulak Burun Boğaz Kliniği, Kütahya

2. Dumlupınar Üniversitesi Tıp Fakültesi, Göz Hastalıkları Kliniği, Kütahya

\section{$\ddot{O Z E T}$}

Amaç: Subperiostal apse; en sik görülen orbital komplikasyondur. Periorbita ile kemik duvar arasında püy birikimi ile karakterizedir. Rinosinüzit komplikasyonu olarak ortaya çıkan ve tedaviye dirençli subperiostal apse olgusunu literatür eşliğinde tartışarak sunuyoruz.

Olgu: On iki yaşında kız hasta üç gün önce başlayan sağ gözde şişlik ve kızarıklık şikayeti ile başvurdu. Muayenesinde proptozis, süpero-lateral baklş kısitlılığ cede ödem, hiperemi ve pürülan sekresyon izlendi. Medikal tedavi ile takip edilen hastanın kliniğinde düzelme olmamasi aksine progresyon göstermesi üzerine endoskopik sinüs cerrahisi yapıld. Takiplerinde rinosinüzit ve proptozisi yeteri kadar gerilemeyen hasta ikinci kez operasyona alınd . Post-op kontrollerinde, proptozisi gerilediği izlendi.

Sonuç: Rinosinüzit komplikasyonu olarak ortaya çıkan subperiostal apse olgularında hastalarda görme kaybl, kavernöz sinüs trombozu, subdural abse ve menenjit gibi mortalite ile seyredebilecek durumlar meydana gelebilmektedir. Medikal tedavi ile yakın takipte bulguları düzelmeyen ya da progresyon gösteren vakalarda uygun cerrahi girişim yapılmalıdır. Tam düzelme olmayan vakalarda "second look (ikincil bakı)" ihtiyacı olabileceği akılda tutulmalıdır.

Anahtar Kelimeler: akut rinosinüzit, subperiostal apse, orbital komplikasyon

\section{ABSTRACT}

Purpose: The most common orbital complication is subperiosteal abscess. It is characterized by accumulation of the pus between periorbita and bone wall. We presented a case with subperiosteal abscess which was resistant to treatment and occurred as a complication of rhinosinusitis in the light of literature.

Case: Twelve years old girl was admitted to outpatient clinics with right eye swelling and hyperemia beginning at 3 days ago. She had proptosis, supero-lateral overview limitation in eye; hyperemia, severe edema and purulent secretion in nasal cavity. Although she was followed up with medical therapy, her proptosis didn't regress, even progressed, so endoscopic sinus surgery was done. Rhinosinusitis and proptosis didn't regress during post-operative follow up, therefore second operation was done. In post-operative follow up, proptosis was resolved.

Result: In patients with subperiosteal abcess as a result of rhinosinusitis complication, patients should be closely monitored. Vision loss, cavernous sinus thrombosis, subdural abscess and meningitis may occur with mortality. If it doesn't regress or progress despite medical therapy, suitable surgery should be applied. In non-full recovery cases, second look is needed.

Keywords: acute rhino sinusitis; subperiosteal abscess; orbital complication

\footnotetext{
İletişim:

Sorumlu Yazar: Dr. Onur Erdoğan

Adres: Dumlupınar Üniversitesi Tıp Fakültesi, Kulak Burun Boğaz Kliniği, Kütahya

E-Posta: onurerdogan.kbb@gmail.com

Makale Geliş: 23.05.2015

Makale Kabul: 04.07.2015

DOI: http://dx.doi.org/10.16948/zktb. 49109
}

Bu vaka, 11. Türk Rinoloji Kongresinde Poster olarak sunulmuştur. 


\section{GİRİŞ}

Sinüzit, klinik olarak nazal kaviteyi ve paranazal sinüsleri döşeyen mukozaların, buradaki sıviların ve/veya alttaki kemiğin ortaya koyduğu enflamatuar cevap olarak tanımlanabilir (1). Rinosinüzit olgularında antibiyoterapinin yaygın olarak kullanılmasına rağmen halen bazı komplikasyonlar görülebilmektedir (2). Enfeksiyonun orbita ve intrakraniyal dokulara hızla yayılmasıyla çok ciddi ve mortalite riski yüksek komplikasyonlar ortaya çıkabilmektedir. Rinosinüzitli hastalarda \% 3 oranında orbital komplikasyon meydana gelebilmektedir (3). Rinosinüzite bağlı orbital komplikasyonlar Chandler'in tarifine göre periorbital sellülit, orbital sellülit, orbital apse, subperiosteal apse ve kavernöz sinüs trombozudur (4). Subperiosteal abse(SA); periorbita ile orbita duvar1 periostu altında püy birikmesi ile karekterizedir (5). Tüm orbital komplikasyonlar arasındaki oranı \%15 olarak bildirilmiștir (6). Tanısı klinik ve radyolojik inceleme ile konulmaktadir (7-8). Tedavide klinik tabloya göre medikal ve cerrahi tedavilerden biri veya kombinasyonu uygulanmaktadır (Tablo 1) (9). Cerrahi müdahale yap1lan olguların \%15.8' inde ikinci bir müdahale gerekebilmektedir (10). Yazımızda rinosinüzit komplikasyonu olarak ortaya çıkan ve tedaviye dirençli SA olgusunu literatür eşliğinde tartışarak sunuyoruz.

\section{Tablo 1. \\ Medial Subperiostal Apsenin Medikal Tedavi Kriterleri}

1. Normal görme, pupil, and retina

\section{Oftalmopleji olmaması}

3. Intraocular basıncın $<20 \mathrm{~mm} \mathrm{Hg}$ olması

\section{Proptozisin $5 \mathrm{~mm}$ veya daha az olması}

5. BT'de genişliğin $4 \mathrm{~mm}$ veya daha az olması

\section{OLGU}

On iki yaşında kız hasta üç gün önce başlayan sağ gözde şişlik ve kızarıklık şikayeti ile göz hastalıkları polikliniğine başvurmuş. Hastanın oftalmolojik muayenesinde sağ gözde proptozis, supero-lateral bakış kısıtlılığ 1 tespit edilmiş. Hospitalize edilen hasta, tarafımıza konsülte edildiğinde nazal kaviteyi obstrükte eden ileri derecede ödem, hiperemi ve pürülan sekresyon KBB muayenesinde tespit edildi.
Yapılan paranazal bilgisayarlı tomografide sağ maksiller, etmoid ve frontal sinüsü tutan rinosinüzit ve subperiosteal apse izlendi. Medikal tedavide $100 \mathrm{mg} / \mathrm{kg}$ /gün seftriakson, $40 \mathrm{mg} /$ $\mathrm{kg} /$ gün metronidazol, topikal dekonjestan ve non-steroid antienflamatuvar verildi. Hastanın kliniğinde 48 saat sonra gerileme olmadi; proptozisinin gerilemedi, göz hareketlerinde kısıtl1l1k devam etti ve görme keskinliği $6 / 10$ olmas1 üzerine endoskopik sinüs cerrahisi kararı alındı (Resim 1, 2, 3).
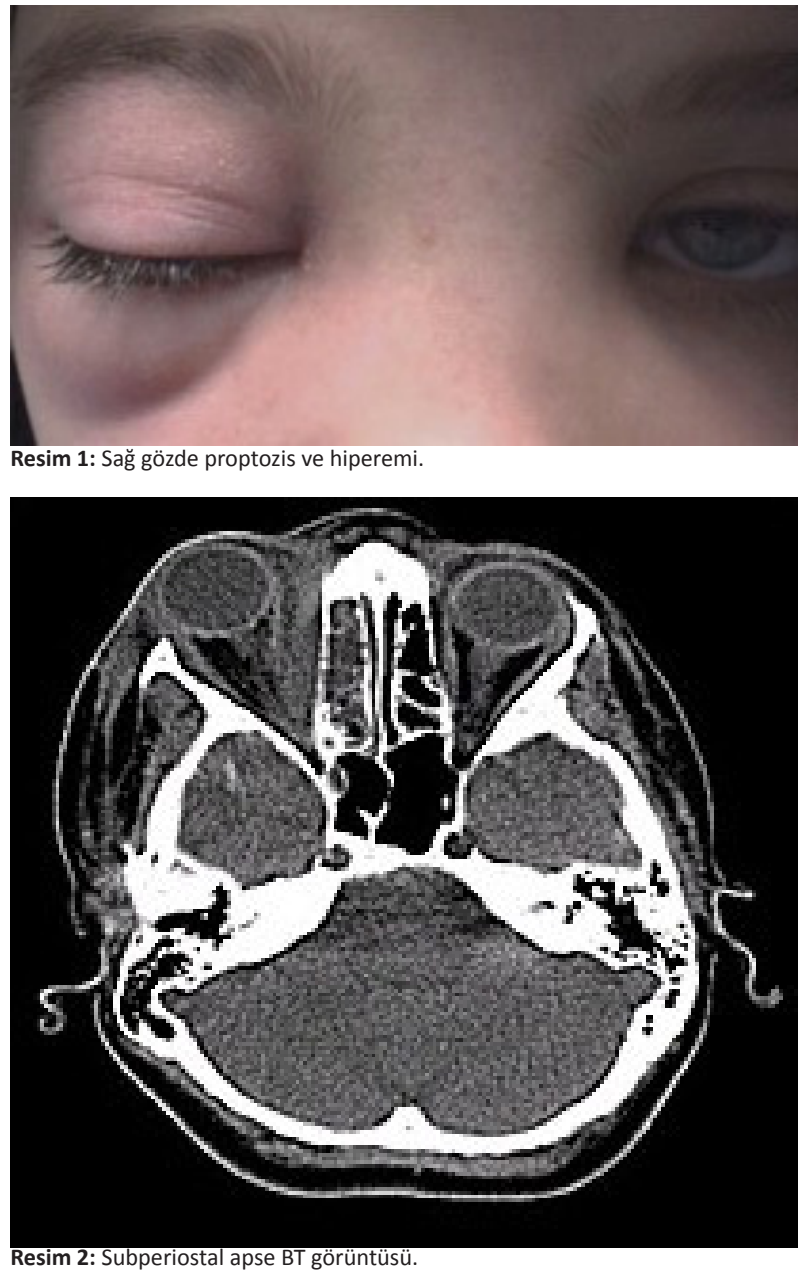

Yapılan müdahalede nazal mukoza ileri derecede ödemli olarak izlendi. Uygun dekonjesyon sağlandiktan sonra klasik endoskopik cerrahi basamaklarına uyuldu. Sağ maksiller sinüs ostiumu açıldıktan sonra ve lamina papireseanın çıkarılmasını takiben 20 cc püy drene edildi. Operasyon sonrası takiplerinde görme kayb1 ve göz hareketlerinde kisitlılığı gerileyen fakat rinosinüzit ve proptozisi yeteri kadar gerilemeyen hasta ikinci kez operasyona alındı.

İkinci operasyonda da endoskopik sinüs cerrahisi tercih edildi. Maksiller sinüsten tekrar püy boşaltıldı, lamina paprisea güdükleri temizlendi ve ödemli yumuşak dokular eksize edildi. Post-op kontrollerinde, proptozisi gerileyen vakanın antibiyoterapi altında takiplerine devam edilmektedir (Resim 4). 

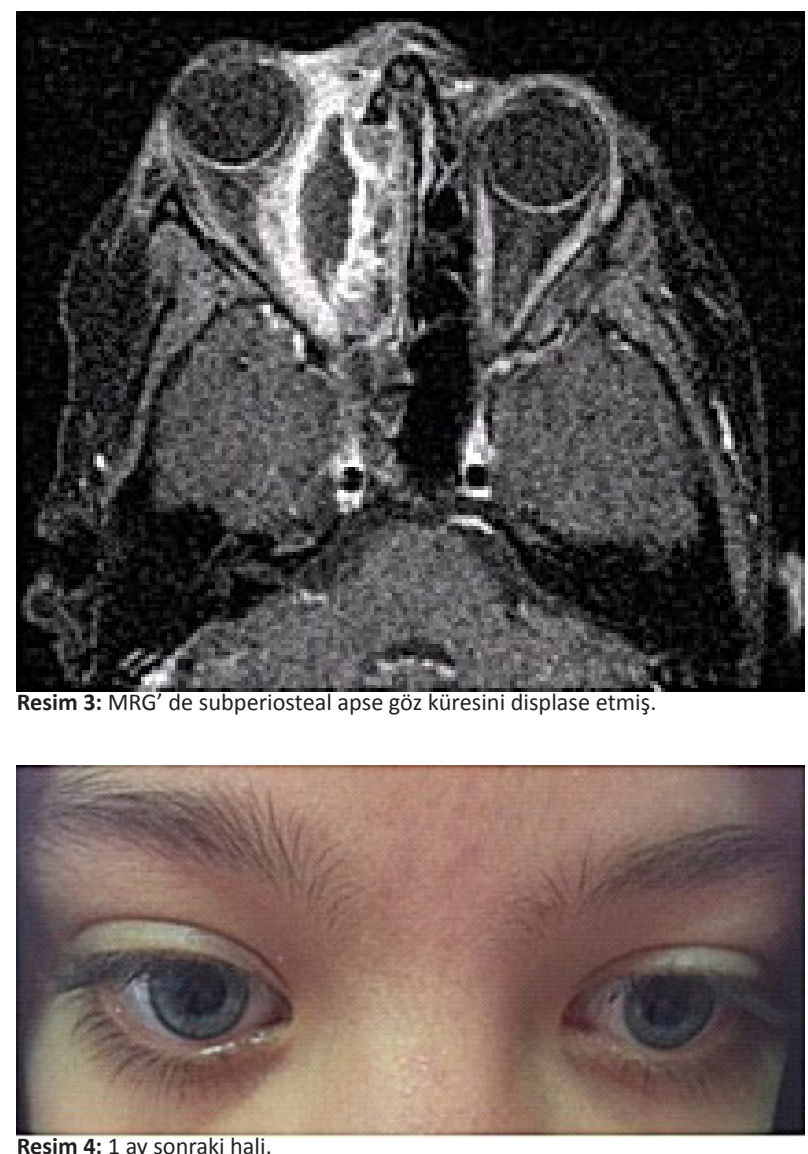

TARTIŞMA

Rinosinüzit, klinik olarak nazal kaviteyi ve paranazal sinüsleri döşeyen mukozaların, buradaki sıvıların ve/veya alttaki kemiğin ortaya koyduğu enflamatuar cevap olarak tanımlanabilir (1). Rinosinüzit olgularında antibiyoterapinin yaygın olarak kullanılmasına rağmen halen bazı komplikasyonlar görülebilmektedir (2). Enfeksiyonun orbita ve intrakraniyal dokulara hızla yayılmasıyla çok ciddi ve mortalite riski yüksek komplikasyonlar ortaya çıkabilmektedir. Rinosinüzit komplikasyonları genellikle çocukluk çağında görülmektedir. Rinosinüzitli hastalarda \%3 oranında orbital komplikasyonlar meydana gelebilmektedir (3). Sinüzite bağlı orbital komplikasyonlar Chandler'ın tarifine göre periorbital sellülit, orbital sellülit, orbital apse, subperiosteal apse ve kavernöz sinüs trombozudur (4). Subperiosteal abse; periorbita ile orbita duvarı periostiumu altında püy birikmesi ile karekterizedir (5). Tüm orbital komplikasyonlar arasındaki oran1 \%15 olarak bildirilmiştir (6).

Hasta toksik görünümdedir, göz dişa ve aşağı yer değiştirmiştir. Antibiyotikler yaygın kulanıma ulaşmadığı dönemlerde, subperiostal apse sırasında görme kaybı ve menenjit riski çok yüksekti. Görme kaybı, septik optik nevrit veya optik sinir, retina, koroid pleksusu besleyen damarlarda tromboemboli nedeniyle olabilir.
Bazen çok hızlı büyüyen apse, gözü öne deplase ederek damarları gerer. Buna bağlı olarak arteriel basınç düşerken, venöz basınç artar. Dolayısıyla intraoküler basınç artışı olur ki; bu durum optik sinir ve retina kanlanmasinı bozar. Böyle durumlarda apsenin derhal boşaltılması, 1şığı bile algılayamayan hastalarda görmenin tamamen düzelmesini sağlayabilir. Siklıkla etmoid sinüslerin tutulumuna bağlı ortaya çıkabilmesinin yanında frontal ve maksiller sinüs tutulumunda da ortaya çıkabilmektedir. Bizim olgumuzda toksik görünümde, sağ gözde proptozis, süpero-lateral bakış kısıtlılığı ve kısmi görme kaybı meydana gelmişti.

SA tanis1 klinik ve radyolojik inceleme ile konulmaktadir (7-8). Radyolojik incelmede bilgisayarlı tomografi (BT) tercih edilmektedir. BT göz küresi, retro-orbital dokular, paranazal sinüslerin durumu hakkında bilgi veririr. Apsenin lokalizasyonu, göz küresindeki itilme, proptozis ve ekstraoküler kaslar görülür. Cerrahi tedavi planlarken Tabarino ve ark. (11) proptozisinin ve apsenin hacmini hesaplamakta ve apsenin hacmi $500 \mathrm{~mm} 3$ 'ten büyükse cerrahi tedavi önermektedirler. İntrakranial komlikasyon düşünülen olgularda yada kavernöz sinüs trombozu düşünülen hastalarda manyetik rezonans görüntüleme önerilmektedir. Tedavide klinik tabloya göre medikal ve cerrahi tedavilerden biri veya kombinasyonu uygulanmaktadır (9). Kimi yazarlar medikal tedavi ile bazı olguların tedavi edilebileceğini bildirken kimi yazarlarda mutlaka cerrahi tedavi ile birlikte medikal tedavi önermektedirler (9). Medial subperiosteal apse medikal cerrahi tedavi kriterleri Oxford ve ark. tarafından belirtilmiştir (Tablo 1). Cerrahi yaklaşımda endoskopik sinüs cerrahisi ve eksternal yaklaşım tercih edilebilmektedir (10). Yazarlar genel olarak eksternal yaklaşımın daha başarılı olduğunu bildirseler de Rubin ve ark. (10) yaptıkları çalışmada iki yaklaşımında eşit başarıları olduğunu iddia etmektedirler.

Bizim olgumuz öncelikle medikal tedavi ile takip edilmiştir. Klinik seyrinde düzelme olmaması aksine progresyon göstermesi üzerine endoskopik sinüs cerrahisi tercih edilmiştir. Cerrahi müdahale yapılan olguların \% 15.8'inde ikinci bir müdahale gerekebilmektedir (10). Bizim olgumuzda da post-operatif 72 saat sonra proptozisde yeterli düzelmeme olması ve rinosinüzit tablosunun devam etmesi üzerine "second look (ikincil bak1)" ihtiyacı ortaya çıkmıştır. İkinci operasyonda maksiller sinüsten tekrar püy boşaltıldı, lamina paprisea güdükleri temizlendi ve ödemli yumuşak dokular eksize edildi. Postoperatif takibinde rinosinüzit bulguları geriledi, proptozis makul ölçüde geriledi. 


\section{SONUÇ}

Rinosinüzit komplikasyonu olarak ortaya çıkan subperiostal apse olgularında hastalar yakından takip edilmelidir. Hastalarda görme kaybı, kavernöz sinüs trombozu, subdural apse ve menenjit gibi mortalite ile seyredebilecek durumlar meydana gelebilmektedir. Medikal tedavi ile yakın takipte bulguları düzelmeyen ya da progresyon gösteren vakalarda uygun cerrahi girişim yapılmalıdır. Tam düzelme olmayan vakalarda "second look (ikincil bak1)" ihtiyacı olabileceği akılda tutulmalıdır.

\section{KAYNAKLAR}

1. Lanza DC, Kennedy DW. Adult Rhinosinusitis defined. Otolaryngol-Head and Neck Surg 1997; 3: 107.

2. Wolf SR, Göde U, Hosemann W. Endonasal endoscopic surgery for rhinogen intraorbital abscess: A report of six cases. Laryngoscope 1996; 106: 105-10.

3. Oliverio PJ, Benson ML, Zinreich SJ. Update on imaging for functional endoscopic sinus surgery. Otolaryngol Clin North Am 1995; 28: 585-608.

4. Chandler JR, Langenbrunner DJ, Stevens ER. The pathogenesis of orbital complications in acute sinusitis. Laryngoscope 1970; 80: 1414-28.

5. Kayhan FT, Sayin I, Yazici ZM, Erdur O. Management of orbital subperiosteal abscess. J Craniofac Surg 2010;21(4):1114-1117

6. Pereira KD, Mitchell RB, Younis RT, et al. Management of medial subperiosteal abscess of the orbit in children-a 5 year experience. Int $J$ Pediatr Otorhinolaryngol 1997;38:247-54

7. Bedwell J, Bauman NM. Management of pediatric orbital cellulitis and abscess. Curr Opin Otolaryngol Head Neck Surg 2011;19(6):467-473.

8. Tanna N, Preciado DA, Clary MS, Choi SS Surgical treatment of subperiosteal orbital abscess. Arch Otolaryngol Head Neck Surg 2008;134(7):764-767

9. Oxford LE, McClay J. Int J Pediatr Otorhinolaryngol. Medical and surgical management of subperiosteal orbital abscess secondary to acute sinusitis in children. 2006;70(11):1853-61.

10. Rubin F, Pierrot S, Lebreton M, Contencin P, Couloigner V. Drainage of subperiosteal orbital abscesses complicating pediatric ethmoiditis: comparison between external and transnasal approaches. Int J Pediatr Otorhinolaryngol. 2013;77(5):796-802

11. Tabarino F, Elmaleh-Bergès $M$, Quesnel S, Lorrot M, Van Den Abbeele T, Teissier N. Subperiosteal orbital abscess: volumetric criteria for surgical drainage. Int J Pediatr Otorhinolaryngol. 2015;79 (2):131-5. 